\title{
Feasibility study of the utilization of waste basalt rebars as fibre reinforcement for concrete
}

\section{Tomasz Kowalik, Dominik Logoń and Andrzej Ubysz}

Wroclaw University of Science and Technology, Faculcy od Civil Engineering, pl. Grunwaldzki 11, 50-377 Wroclaw, Poland

\begin{abstract}
Composite materials have been gaining increasing popularity in many industries, such as: the automotive industry, aviation, electrotechnics and construction. Due to the widespread use of composites the problem of their utilization and reuse arises. This paper presents an attempt to utilize basalt discards as fibre reinforcement for concretes.
\end{abstract}

\section{Introduction}

Fibre reinforced polymer (FRP) composites entered the world of civil engineering structures in the early 1990s, mainly in the USA, Japan and Western Europe. The composites are principally used as reinforced concrete bars and external reinforcements for structures.

An FRP material consists of (typically carbon, aramid or basalt) fibres embedded in a polymer matrix. Considering their light weight, such materials are characterized by very high strength. The tensile strength of selected FRP materials is compared with that of reinforcing steel in table 1.

Table 1. Strength parameters of selected fibres.

\begin{tabular}{|c|c|c|c|c|}
\hline \multirow{2}{*}{ Type of fibre } & Diameter & Density & $\begin{array}{c}\text { Tensile } \\
\text { strength }\end{array}$ & $\begin{array}{c}\text { Elastic } \\
\text { modulus }\end{array}$ \\
\cline { 2 - 5 } & $\mathbf{m m}$ & $\mathbf{k g} / \mathbf{d m}^{3}$ & $\mathbf{M P a}$ & $\mathbf{G p a}$ \\
\hline carbon & $0.050-0.160$ & $2.5-2.9$ & 4500 & 253 \\
\hline glass & $0.010-0.015$ & 2.6 & 2500 & 80 \\
\hline basalt & $0.010-0.020$ & $2.6-2.8$ & 4840 & 80 \\
\hline polypropylene & $0.011-0.200$ & $0.90-0.91$ & $200-600$ & $3-5$ \\
\hline steel & $0.1-1$ & 7.85 & $500-2000$ & 210 \\
\hline
\end{tabular}

Besides their high strength, the fibres also show insusceptibility to corrosion, magnetic neutrality and do not disturb electromagnetic waves, which is particularly useful in 
locations close to precision devices. As the demand for various FRP materials keeps growing, the problem of their recycling arises. The recycling of the composites can be divided into mechanical, raw-material and thermal recycling. In most cases the recycling of such materials is a complicated and energy-intensive process. The aim of this research was to look into the possibility of the reuse of polymer composites at a minimum labour and energy input.

\section{Fibres recovered from defective basalt rebars}

Defective basalt rebars were used in this study. The following classification of rebar defects was adopted:

a) An uneven and imprecise rebar resin coating, resulting in the poor adhesion of the composite rebar to concrete and in no interaction between the basalt fibres. The strength of a rebar made up fibres depends largely on the adhesive forces between the fibres and the resin. In some types of rebars the surface of the fibres is specially prepared in order to increase adhesion between the fibres and the resin (fig. 1);

b) Internal rebar fractures, resulting from the merger of microcracks present in the internal structure of rebars (fig. 2);

c) Non-rectilinearity of individual rebars (fig. 3).
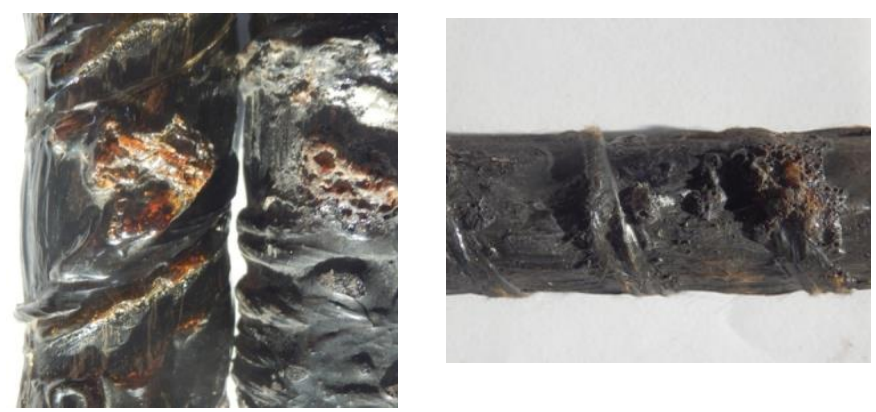

Fig. 1. Uneven distribution of resin and its burn-through.
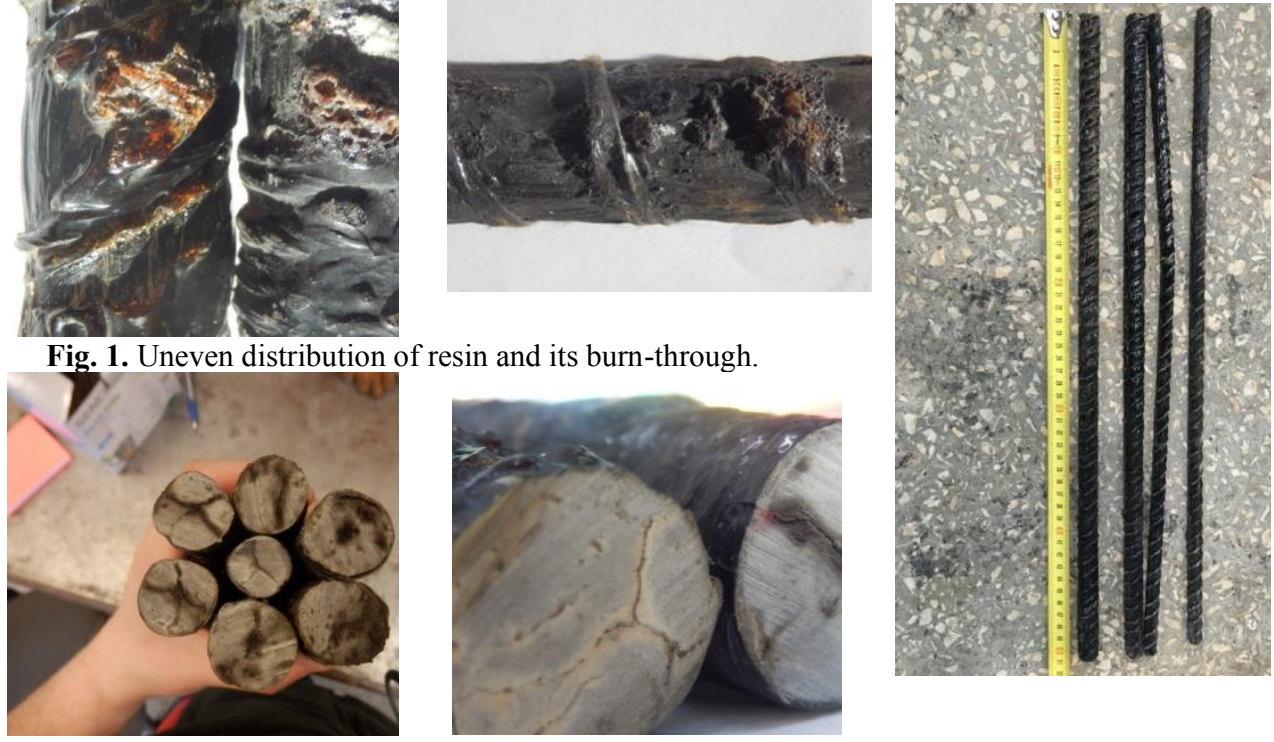

Fig. 2. Fractures in rebar cross section.

Fig. 3. Non-rectilinearity of rebars.

A major factor considered by the authors when developing a method of separating out fibres from basalt rebars was the possibly lowest labour intensity and energy consumption of the method. The recycling of the materials should be as little labour-intensive as possible and their processing and making them suitable for reuse should consume minimum energy. When the two considerations are taken into account, this can contribute to a wider and greater use of composite discards in the construction industry.

As part of the preparation of samples, composite rebars were cut into $50 \mathrm{~mm}$ long sections. The length was based on analyses of the literature on steel fibres, and on the 
finding that during the industrial-scale preparation of a concrete mix and while placing fibre concrete from a concrete mixer longer fibres cause technological problems (e.g. they deposit on the pump's strainer).

The following procedure was found to be most effective. The cut basalt rebar sections were placed in a climatic chamber and subjected to heat treatment at the temperature of $250^{\circ} \mathrm{C}$. The resin bonding the fibres softened under the high temperature whereby further processing became possible. The rebar's ribs (contributing to better concrete-rebar bonding) debonded under the high temperature and so they were removed.

The desired shape and structure of rebar shreds was obtained by pressing the heated up rebar sections through blades set crosswise. The device made for this purpose is shown in fig. 4.

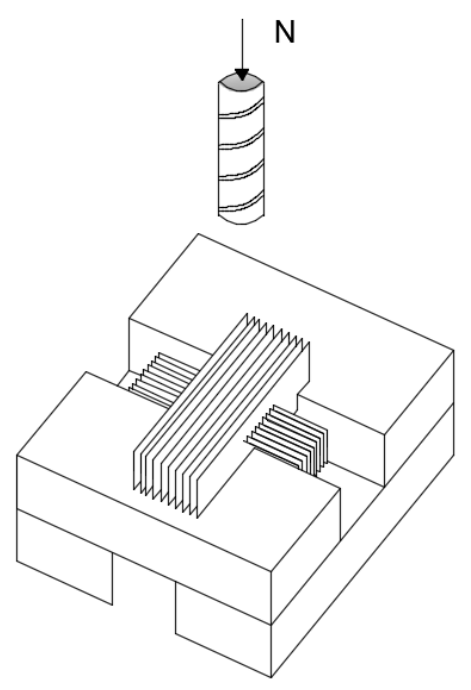

Fig. 4. Diagram illustrating rebar shredding.

By pressing the rebar sections through the set of blades $4 \times 4 \times 50 \mathrm{~mm}$ shreds (photo 5) were obtained.
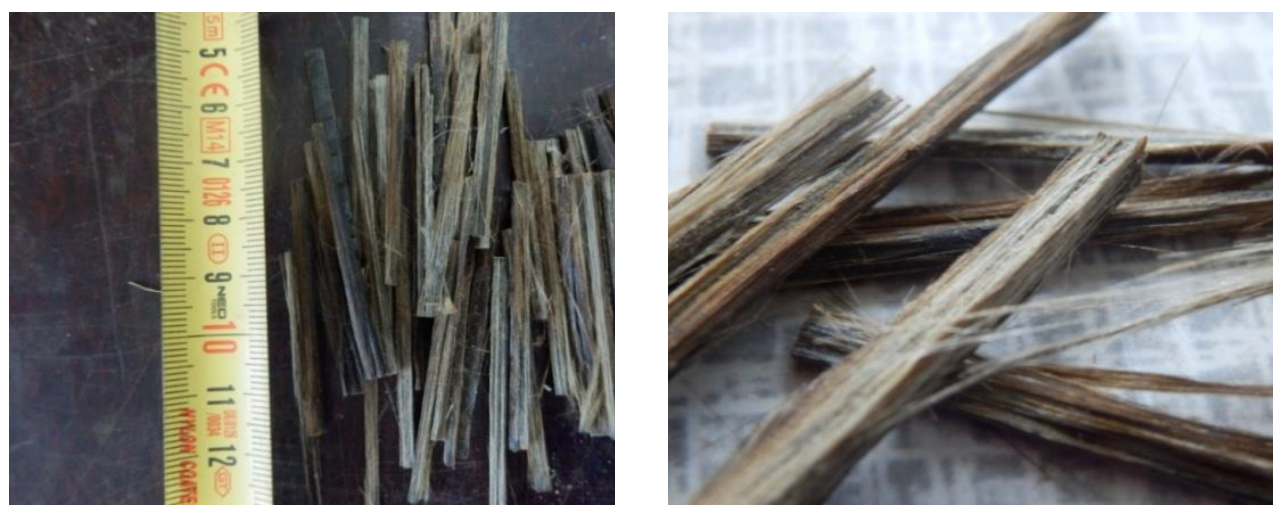

Fig. 5. Basalt fibres obtained by shredding rebar sections. 


\section{Static tension tests}

Static tension tests were carried out to determine the strength parameters of the fibres. The tested fibres were $120 \mathrm{~mm}$ long. In order to protect the fibres from crushing in the strength testing machine the fibres were placed in internally threaded sleeves and the latter were filled with epoxy resin Sikafloor 156. Considering the fluid consistency of the resin, a good connection between the tested fibre and the sleeve was ensured.

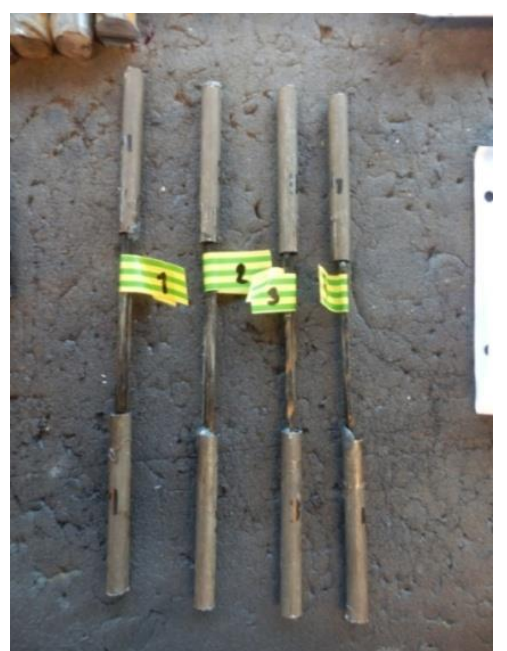

Fig. 6. View of specimens prepared for tensile strength testing.

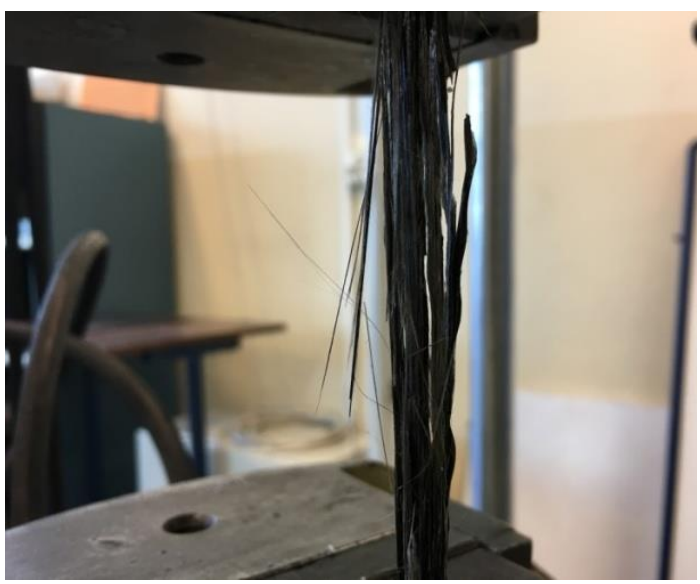

Fig. 8. Photo of failed specimen.

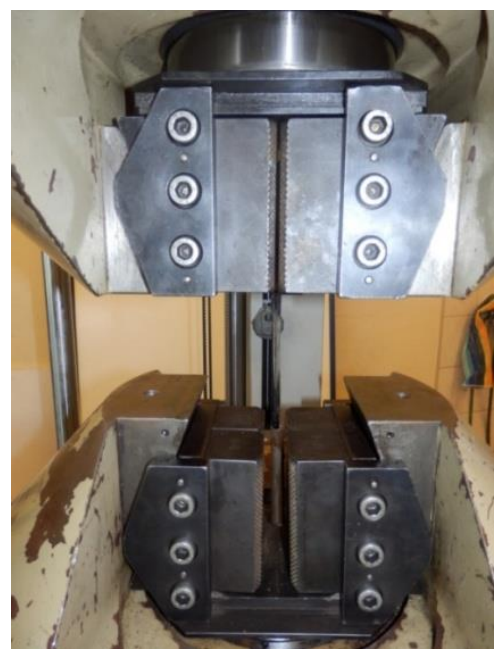

Fig. 7. Specimen placed in strength testing machine.

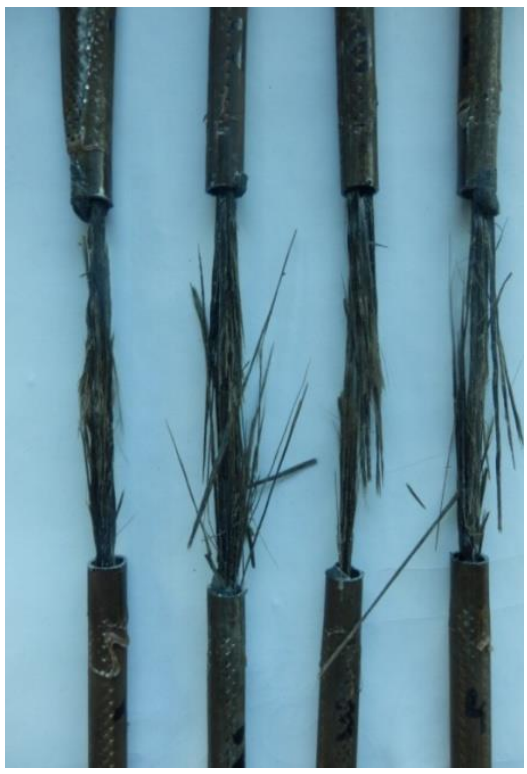

Fig. 9. View of failed specimens.

The static tension tests yielded the results presented in table 2 . 
Table. 2. Tensile strength test results.

\begin{tabular}{|c|c|c|c|c|}
\hline \multirow{2}{*}{ No. } & \multirow{2}{*}{ Specimen } & Surface area & Force & Strength \\
\hline & & $\mathbf{m m}^{2}$ & $\mathbf{N}$ & MPa \\
\hline \multirow{2}{*}{1} & \multirow{2}{*}{ 001' } & 7.0291 & \multirow{2}{*}{2537.69} & \multirow{2}{*}{312.8991} \\
\hline & & 9.1914 & & \\
\hline 2 & 002' & 18.3809 & 9559.73 & 520.0904 \\
\hline 3 & 001 & 18.1952 & 8111.12 & 445.7835 \\
\hline 4 & 002 & 18.9626 & 15702.1 & 828.0563 \\
\hline 5 & 003 & 18.3008 & 8176.46 & 446.7816 \\
\hline 6 & 004 & 22.74115 & 12445.5 & 547.2678 \\
\hline
\end{tabular}

\section{Compression strength tests}

In order to determine the effect of an addition of recycled basalt fibres on the compressive strength of the concrete, $150 \times 150 \times 150 \mathrm{~mm}$ cube specimens with a $1 \%$ recycled basalt fibres addition and without a fibre addition were made. The test results obtained after 28 days since casting are presented in tables 3 and 4.

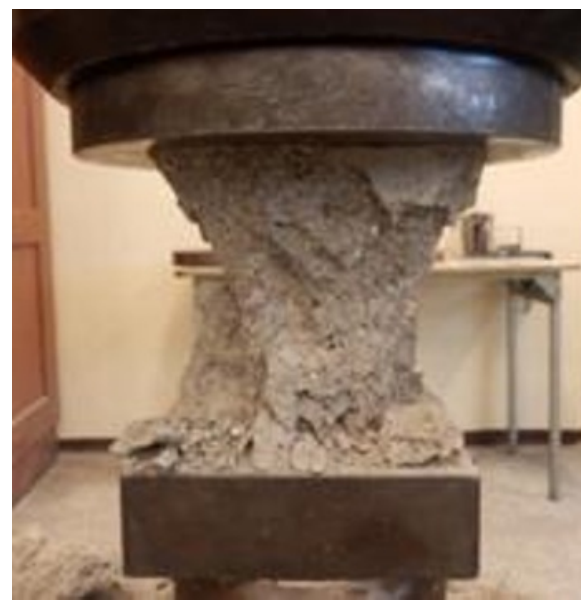

Fig. 10. View of failed concrete specimen.

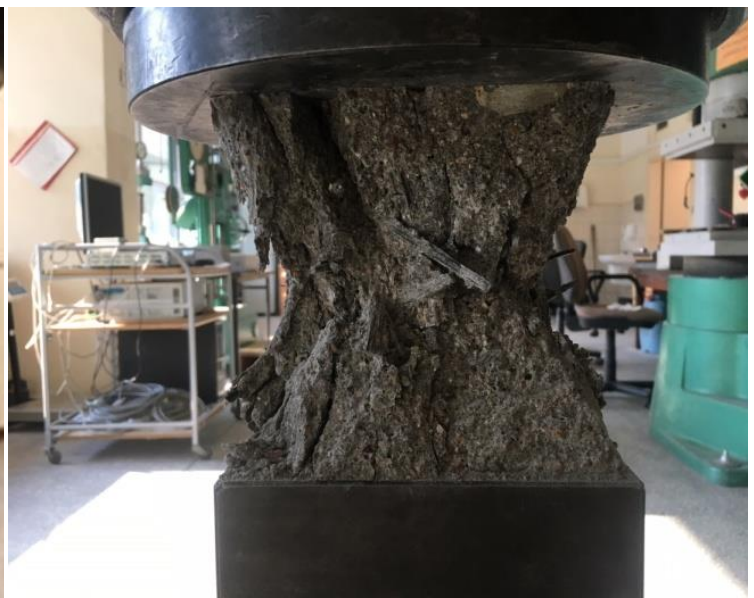

Fig. 11. View of failed concrete specimen with basalt fibres addition.

Table 3. Results of compression testing of concrete cubes.

\begin{tabular}{|c|c|c|c|c|c|c|c|c|}
\hline \multirow{2}{*}{ No. } & \multicolumn{2}{|c|}{ Side } & \multirow{2}{*}{ Height } & \multirow{2}{*}{$\begin{array}{c}\text { Surface } \\
\text { area }\end{array}$} & Weight & $\begin{array}{c}\text { Ultimate } \\
\text { force }\end{array}$ & $\begin{array}{c}\text { Compressive } \\
\text { strength }\end{array}$ & $\begin{array}{c}\text { Average } \\
\text { strength }\end{array}$ \\
\cline { 2 - 8 } & \multicolumn{2}{|c|}{$\mathbf{m m}$} & $\mathbf{m m}$ & $\mathbf{m m}^{\mathbf{2}}$ & $\mathbf{k g}$ & $\mathbf{k N}$ & $\mathbf{M p a}$ & Mpa \\
\hline 1 & 150.34 & 150.89 & 150.42 & 22685.05 & 7.5960 & 900 & 39.6737 & \multirow{2}{*}{41.0801} \\
\hline 2 & 150.31 & 150.38 & 150.16 & 22603.87 & 7.5950 & 960 & 42.4706 & \\
\hline 3 & 149.50 & 149.75 & 150.33 & 22386.63 & 7.5915 & 920 & 41.0960 & \\
\hline
\end{tabular}


Table 4. Results of compression testing of concrete cubes with added recycled basalt fibres.

\begin{tabular}{|c|c|c|c|c|c|c|c|c|}
\hline \multirow{2}{*}{ No. } & \multicolumn{2}{|c|}{ Dimension } & \multirow{2}{*}{ Height } & $\begin{array}{c}\text { Surface } \\
\text { area }\end{array}$ & Weight & $\begin{array}{c}\text { Ultimate } \\
\text { force }\end{array}$ & $\begin{array}{c}\text { Compressive } \\
\text { strength }\end{array}$ & $\begin{array}{c}\text { Average } \\
\text { strength }\end{array}$ \\
\cline { 2 - 8 } & $\mathbf{A}$ & $\mathbf{~} \mathbf{m}$ & $\mathbf{m m}$ & $\mathbf{m m}^{\mathbf{2}}$ & $\mathbf{k g}$ & $\mathbf{k N}$ & $\mathbf{M P a}$ & $\mathbf{M P a}$ \\
\hline 1 & 151.81 & 149.99 & 149.65 & 22769.48 & 7.667 & 845 & 37.1111 & \\
\hline 2 & 150.28 & 149.43 & 149.66 & 22456.59 & 7.627 & 855 & 38.0735 & \multirow{2}{*}{38.8543} \\
\hline 3 & 149.96 & 149.88 & 149.83 & 22475.51 & 7.590 & 930 & 41.3784 & \\
\hline
\end{tabular}

A comparison of the test results shows that the average compressive strength of the concrete specimens with the addition of recycled basalt fibres is lower than that of the concrete without fibres. Similar findings are often reported in the case of a steel fibres addition.

\section{Tensile strength in bending}

In order to find out if the obtained fibres can be used as fibre reinforcement for concrete in members (beams) under bending, concrete specimens with a recycled basalt fibres addition and reference concrete specimens were made. Since there are no reports on the reinforcing concrete with this kind of fibres, pilot studies were carried out using $100 \times 100 \times 400 \mathrm{~mm}$ prisms with a $1 \%$ basalt fibres addition. The fine-grained concrete was made using Portland cement (CEMII).

\subsection{Test stand}

Tests were carried out on the $100 \times 100 \times 400 \mathrm{~mm}$ specimens as shown in the diagram below (fig. 12).

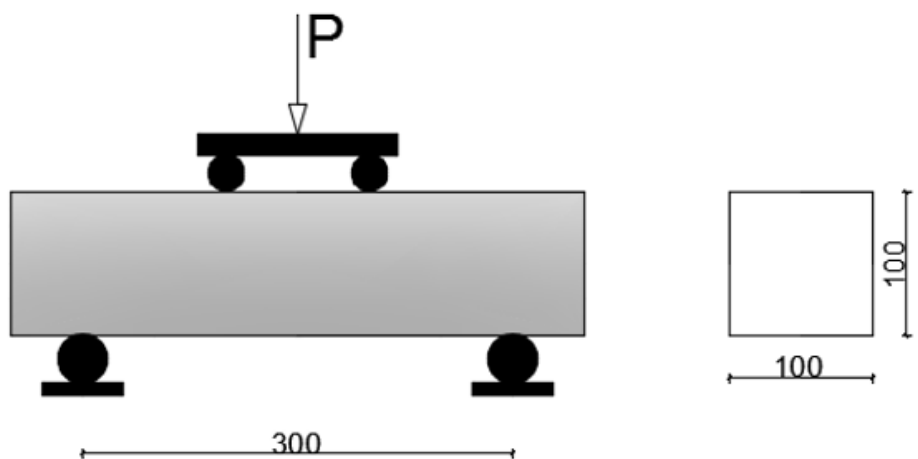

Fig. 12. Flexural strength test diagram (4P).

In order to increase the measurement accuracy, inductive sensors were installed to record the neutral axis initial position invariability on the axes of the supports. 


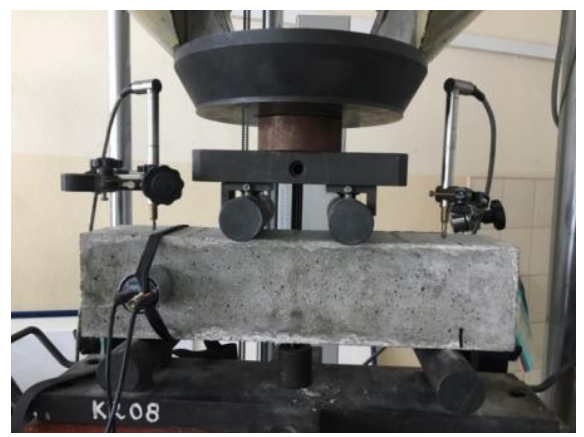

Fig. 13. View of specimen on measuring stand.

\subsection{Specimens with recycled basalt fibres addition}

The character of the cracking of the specimens with added recycled basalt fibres is different than that of the reference concrete specimens. In the case of the tested specimens with the $1 \%$ basalt fibres content, the tensile force transmission capacity (tensile strength) until the first cracking did not improve visibly. Whereas the effect of the fibres on the beyond-theelastic range properties of the specimens is significant. As opposed to the bending of the prisms made of concrete with no addition of fibres, the specimens made of fibre reinforced concrete can transfer considerable tensile loads after cracking and show a visible increase in their fracture resistance in comparison with the prisms made of concrete without any fibres addition.

One type of specimens, i.e. with a fibres content of $1 \%$, was used in the tests. Because of the quite considerable weight of the individual shreds, the fibres content in the concrete specimen volume is relatively low, which is particularly visible after the specimen fails. This entails the risk that the fibres will be unevenly distributed or totally absent in the specimen's cross sections. Despite the small amount of fibres in the concrete, the specimens showed a high tensile load transferring capacity after the maximum tensile force had been reached, as can be seen in fig. 14 .

Figure 14 shows the dependence between the load bearing capacity of the specimens in the tension zone and their displacement for both the concretes with and without the basalt fibres addition. The specimens would fail due to: the pulling out of the fibres from the concrete and the rupture of the fibres.

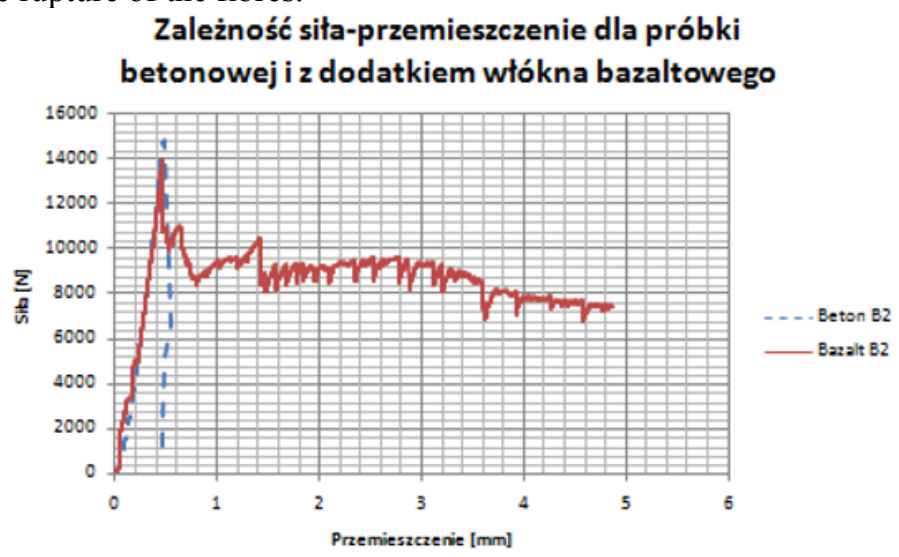

Fig. 14. Force-displacement dependence for concrete specimen and specimen with basalt fibres addition. (Force, Displacement, Concrete B2, Basalt B2, Force-displacement dependence for concrete specimen and specimen with basalt fibres addition) 


\subsection{Specimens with recycled steel fibres addition}

In order to compare the basalt fibres used as reinforcement fibres for concrete, specimens with the same dimensions and grade of concrete with a $1 \%$ addition of steel fibres were made. The way in which they failed differed from that of the prisms with the basalt fibres addition. The failure proceeded less rapidly than in the case of the prisms with basalt shreds. The behaviour of the specimen from the first cracking until its total failure was continuous. The specimen failed due to both the pulling out of the fibres from the concrete and the rupture of the fibres. Figure 16 shows the force-displacement dependence for the steel fibre reinforced concrete specimens. The latter were able to transmit much greater forces than the specimens with the basalt fibres addition. The continuous behaviour of the specimen is visible in the figure. After the maximum force is reached it does not fall rapidly to the lowest value, but decreases in a gentler way.

\section{Conclusion}

The pilot studies carried out on basalt fibres recovered from composite rebars and used as fibre reinforcement for concrete have shown that the fibres do not improve its compressive and tensile strength properties. Nevertheless, the finding that when the tensile strength is exceeded, the material does not fail abruptly, but at an elongation exceeding ten times the ultimate elongation for concrete, the load-bearing capacity of the latter remains at a level $50 \%$ higher than its original strength, is significant.

Additional positive findings are as follows: besides increasing the strength of concrete in the post-critical zone, the fibres are also insusceptible to corrosion, magnetically neutral and do not disturb electromagnetic waves. In construction this is particularly useful in the case of members situated close to precision devices or being in service in (chemically) aggressive environments (catenary poles, telecommunication masts, etc.).

A major aspect is the protection of the environment. As the demand for various FRP materials keeps growing, the problem of their recycling arises. The recycling of the composites can be divided into mechanical, raw-material and thermal recycling. In most cases the recycling of such materials is found to be a complicated and energy-intensive process. Therefore the conclusions indicating the possibility of the passive utilization of such waste materials (which even though they do not increase the strength of the structure, they do not significantly worsen its physicochemical properties) are of major importance.

Further research in this regard is aimed at the effective (both passive and active) recycling of such waste materials. Another important aspect of this study is the profitability assessment from the points of view of the improvement of the physicochemical properties and the direct costs and the energy intensiveness of the recycling and production processes.

This paper has been written as part of the research project: "Industrialized construction process (Construction 4.0). Technological and methodological conditions of application of selected composite elements in civil engineering". The project is being carried out jointly with Peoples' Friendship University of Russia in Moscow. Research project PWr-RUDN 2017 no. 45WB / 0001/17 Industrialized Construction Process.

\section{References}

1. Jamroży Z.: Steel-wire reinforced concrete, Course book for students at technical universities (in Polish), Cracow (1985) 
2. Glinicki M.A.: Embrittlement mechanisms and durability of cementitious composites with fibreglass (in Polish). Institute of Fundamental Research, Polish Academy of Sciences, Warsaw (1999)

3. Katzer J.: Concretes with fibre reinforcement (in Polish). XXXIIIrd All-Poland Workshop for Designers of Structures, Szczyrk 6-9 March 2018.

4. Glinicki M.A.: Concrete with structural reinforcement (in Polish). XXVth All-Poland Workshop for Designers of Structures, Szczyrk 10-13 March 2010.

5. High C., Seliem H., M., El-Safty A., Rizkalla S.,H.: Use of basalt fibres for concrete structures. Construction and Building Materials 96 (2015), pp. 37-46.

6. Glinicki M.A.: Evaluation and design of fibre reinforced concretes based on equivalent strength (in Polish). Drogi i Mosty, No. 3. (2002) 